\title{
PERFILES DE UN GRUPO ECLESIÁSTICO: LOS CANÓNIGOS ARAGONESES DEL ÚLTIMO TERCIO DEL SIGLO XVIII ${ }^{1}$
}

\author{
POR \\ José MANUEl LATORRe CiRIA \\ Universidad de Zaragoza
}

\begin{abstract}
RESUMEN
En este texto se aborda el estudio de los canónigos de las catedrales aragonesas a partir de los informes remitidos por los obispos al confesor real, con la finalidad de conocer cuáles eran los clérigos merecedores de acceder a puestos superiores. Con ellos se puede ofrecer un panorama acerca de su número, edad, origen social y geográfico, formación intelectual, formas de acceso a la canonjía, trayectorias profesionales y conducta. En Aragón parecen observarse algunas diferencias con respecto a otros cabildos españoles, por ejemplo en la menor presencia de canónigos de origen noble o principal y en un acceso a las prebendas no tan controlado localmente como en otros lugares.
\end{abstract}

PALABRAS CLAVE: Iglesia, clero, catedrales, cabildos, Aragón

\section{FEATURES OF A CHURCH GROUP: THE ARAGONESE PREBENDERY IN THE LAST THIRD OF THE $18^{\text {TH }}$ CENTURY}

\begin{abstract}
This paper examines the Aragonese cathedral canons from the reports sent by the bishops to the royal confessor so that he could know what priests deserved to be promoted. This information can supply a view on the canons' number, age, social and geographical origin, education, as well as their ways of access to the canonry, and their professional direction and conduct. In Aragon there appear to
\end{abstract}

${ }^{1}$ El presente estudio forma parte del Proyecto Coordinado del Ministerio de Ciencia y Tecnología $n^{\circ}$. BHA 2001-3300-C03-03 y de los trabajos del grupo Blancas, reconocido por el Gobierno de Aragón. 
be some differences with regard to other Spanish chapters; for instance, there were fewer canons of noble or principal origin, and the access to prebends was not so controlled as it was in other places.

KEY WORDS: The church, the clergy, cathedrals, chapters, Aragon.

Recibido/Received 22-04-2008

Aceptado/Accepted 14-07-2008

La Iglesia española de la Edad Moderna, y la del mundo católico en general, ocupaba en la sociedad un lugar muy distinto al actual, disfrutaba de una posición social privilegiada y gozaba de un poder político y económico sin parangón con el presente. Su papel como guía espiritual de las masas era la base de sustentación de su poder e influencia. El clero señalaba el camino por donde el creyente había de transitar para hallar la preciada meta, la salvación eterna. Los eclesiásticos controlaban la mayor parte de la educación, se ocupaban de la gestión de la beneficencia, alimentada por la caridad individual, y difundían un tipo de religiosidad donde su papel como intermediarios ante Dios era casi imprescindible. Eran los administradores de la fe, de la salvación, en un mundo donde la religión impregnaba la vida de las personas, donde la increencia ocupaba un lugar minoritario. El control de lo sagrado era la herramienta fundamental en manos del clero ${ }^{2}$.

A pesar del importante papel religioso, social, político, económico y cultural jugado por la Iglesia en la vida del país, los estudios sobre la misma fueron durante mucho tiempo escasos en calidad y cantidad. Domínguez Ortiz señalaba en 1970 lo siguiente: «Nos enfrentamos, pues, con el hecho increíble de que una nación cuya historia está íntimamente ligada a la Iglesia Católica no tiene una historia eclesiástica que pueda calificarse siquiera de mediana $»^{3}$. Su obra sobre el estamento eclesiástico en el siglo XVII es una aportación fundamental que marca el inicio de una nueva época en los estudios sobre la Iglesia española. Desde entonces se abre camino una nueva historia desarrollada frecuentemente por laicos y atendiendo a los nuevos métodos de la disciplina histórica. La renovación historiográfica en este campo ha producido abundantes frutos que Cortés Peña valoró en su trabajo sobre «Domínguez Ortiz y la historia social de la Iglesia», donde recoge lo fundamental de la producción científica española en torno a la Iglesia hasta mediados de los noventa ${ }^{4}$.

\footnotetext{
${ }^{2}$ Ch. HiLl, La revolución inglesa 1640, Barcelona, 1977, p. 18. PÉREZ ZAGORIN, Revueltas y revoluciones en la Edad Moderna. I. Movimientos campesinos y urbanos, Madrid, 1985, p. 177. A. GuERREAU, El Feudalismo. Un horizonte teórico, Barcelona, 1984, pp. 231-232.

${ }^{3}$ A. Domínguez Ortiz, La sociedad española en el siglo XVII. II. El estamento eclesiástico, Madrid, 1970, p. 3.

${ }^{4}$ A. L. CoRTÉs PeÑa, «Domínguez Ortiz y la historia social de la iglesia», Manuscrits, 14 (1996), pp. 39-57.
}

Hispania Sacra, LXI

124, julio-diciembre 2009, 545-569, ISSN: 0018-215-X 
Los trabajos sobre los cabildos catedralicios eran en 1970 prácticamente inexistentes. Faltaban monografías a partir de las cuales se pudiera trazar un panorama general de estas instituciones y del clero residente en las mismas 5 . Hoy, sin embargo, se puede decir que las catedrales han sido objeto de investigación, desde distintos puntos de vista y con mayor o menor profundidad, contándose con estudios sobre las sedes de Toledo, Lugo, Palencia, Murcia, Lérida, Jaén, Valladolid, Barcelona, Cádiz, Salamanca, Gerona, Tarragona, Huesca, Granada, Córdoba, Málaga, Santiago de Compostela o León ${ }^{6}$. A pesar de todo, como escribe R. Sánchez, los estudios todavía son insuficientes «... dado el protagonismo destacado de los cabildos en la historia eclesiástica, que es tanto como decir, en la propia sociedad española, profundamente marcada por la religiosidad ${ }^{7}$.

La realidad de las catedrales y de los cabildos eclesiásticos que las gobernaban es compleja, variada, rica en matices, como la de la Iglesia en su conjunto. El papel de los capítulos en la vida de las diócesis era importante, así como su influencia en las ciudades donde tenían su sede, probablemente mayor en las pequeñas que en las grandes, donde otras instituciones podían eclipsar su presencia social.

Los cabildos estaban formados por los canónigos y las dignidades; además de ellos, en las catedrales había otro tipo de clérigos, denominados racioneros, beneficiados o capellanes, los cuales no formaban parte del cabildo, que era gobernado exclusivamente por los primeros. Los cabildos fueron definidos por Muniz como un «colegio de clérigos instituidos en las Iglesias Catedrales para dar a Dios un culto más solemne; para auxiliar al Obispo como su senado y consejo, y para suplirle en el régimen de la diócesis» ${ }^{8}$.

Afirma Antonio García que los cabildos «constituyeron el consejo ordinario del obispo y fueron sus cooperadores en el régimen de las diócesis». Su misión podría resumirse en tres puntos: dirección de la diócesis durante la sede-vacante; elección episcopal, excepto cuando se inmiscuía el poder civil o el metropolitano, cosa habitual, y el asesoramiento al obispo en el gobierno general de la diócesis9.

Según José Luis Martín, no conviene olvidar su papel como instrumentos de cultura y de promoción de brillantes ceremonias de culto, en las que centraron en muchos momentos su función ${ }^{10}$.

\footnotetext{
${ }^{5}$ A. Domínguez OrTIZ, op. cit., p. 40.

${ }^{6}$ Vid. referencias bibliográficas al final del trabajo.

${ }^{7}$ R. SÁnCHEZ GonZÁLEZ, Iglesia y sociedad en la Castilla moderna. El cabildo catedralicio de la sede primada (siglo XVII), Toledo, 2000, p. 9.

${ }^{8}$ T. Muniz, Derecho capitular. Cabildos Catedrales y Colegiales, Sevilla, 1917, p. 35.

${ }^{9}$ A. García y García, Historia del Derecho Canónico. I. El Primer Milenio, Salamanca, 1967, pp. 381-382.

10 J. L. Martín Martín, El Cabildo de la Catedral de Salamanca (s. XII-XIII), Salamanca, 1975, pp. 20-21.
} 
Pero los cabildos no sólo son centros de vida espiritual, lo son también de poder e influencia social, acumulan importantes rentas que permiten una holgada vida a sus miembros. Algunos ejercen como señores de vasallos. En suma, el rol cultural, social, religioso y económico jugado por los cabildos es rico y complejo.

El Concilio de Trento se ocupó en algunos decretos de reforma de los cabildos, limitando sus atribuciones y aumentando el control episcopal sobre ellos. Eso motivó no pocos pleitos entre estas instituciones y los respectivos prelados. Introdujo además Trento la obligación de instituir en las catedrales una canonjía, la lectoral, que debía ser ocupada por alguien capaz de enseñar Sagrada Escritura, y un canónigo penitenciario, con formación suficiente en teología o en derecho canónico ${ }^{11}$.

La vida de los canónigos se ha asociado frecuentemente con un tipo de «buena vida» representado por el poco trabajar, el buen comer y un cierto lujo en el vestido y el alojamiento; también con un cierto brillo intelectual. El disponer de tiempo libre permitió a un sector de los mismos dedicarse al cultivo del estudio de la teología, el derecho, la literatura o el arte ${ }^{12}$. Las buenas ganancias económicas que ofrecían los canonicatos, con diferencias entre unos y otros amplísimas, atraían seguramente hacia ellos a personas más interesadas en la renta que en la misión pastoral. Esta situación produce severas críticas incluso dentro del mundo eclesiástico. Así, Juan de Ávila, en sus «Advertencias» al Concilio de Trento (1551 y 1561), se explaya afirmando que «Cerca de la vida de dignidades, canónigos y racioneros, cosa conocida es a todos que la fábula del mundo, y el terreno de los legos, y el escándalo común de la Iglesia son ellos; pues, por la mayor parte, ni predican, ni leen, ni confiesan, ni aun dicen misa casi en todo el año; y muchos viven con deshonestísima compañía, sin que nadie sea parte para podérsela quitar. Y son algunos tan desvergonzados, que en trajes profanos y aderezos de sus personas compiten con los más profanos del mundo. Y aun cantar en un coro, siendo tan fácil, no lo saben o no lo quieren hacer. Y estos que tan poco aprovechan en la Iglesia, se llevan el mejor bocado de ella, quitándolo a otras personas que fueran dignas y de la boca de los pobres...»13.

\footnotetext{
${ }^{11}$ Concilio de Trento, Sesión V, Decreto sobre la reforma, Cap. I (Qué se establezcan cátedras de Sagrada Escritura) y Sesión XXIV, Decreto sobre la reforma, Cap. VIII (Impóngase penitencias públicas a los públicos pecadores, si el obispo no dispone otra cosa. Institúyase un penitenciario en las catedrales).

12 «La vida de canónigo era una expresión que entonces tenía cierta realidad: sin obligación de cura de almas, sin preocupaciones materiales agobiantes, la misa y el coro, paseos y honestas tertulias llenaban su sosegada existencia. Tal vez esta tranquilidad y abundancia de tiempo libre fomentaran la división en bandos y el afán disputador y pleitista que aquejó a no pocos cabildos. Pero no faltaron los capitulares que como Rioja, Pablo de Céspedes, Góngora y Alonso Cano, dieron a sus ocios más noble empleo»; A DomíngUEZ ORTIZ, op. cit., p. 41.

${ }_{13}$ J. de Ávila, Obras completas, Tomo VI, Madrid, 1971, p. 49.
}

Hispania Sacra, LXI

124, julio-diciembre 2009, 545-569, ISSN: 0018-215-X 
Naturalmente, en un sector tan nutrido como el de los canónigos y las dignidades de las catedrales, unos 2.500 individuos a comienzos del siglo XVII ${ }^{14}$, pueden encontrarse tipos muy diversos. El conocimiento preciso de quiénes eran, cual era su formación y otros detalles de sus vidas y trayectorias ha avanzado en los últimos años merced a los datos aportados por diversas fuentes, como los expedientes de limpieza de sangre, los protocolos notariales o los datos que sobre los propios capitulares guardan las instituciones donde ejercieron su labor. Hoy disponemos de datos importantes sobre una serie de cabildos, como son los de Santiago de Compostela, Toledo, Cádiz, Jaén, Barcelona, Tarragona o Granada ${ }^{15}$.

Estos estudios, construidos con fuentes más o menos ricas, parecen llegar a ciertas conclusiones relativamente uniformes respecto a diversos aspectos sociológicos del colectivo. El origen social predominante es de tipo noble o bien de las principales familias de notables locales. Se accede a las canonjías por coadjutoría y resigna, abundan las relaciones clientelares encabezadas por los obispos o por prebendados en ejercicio, lo que demuestra la existencia de cierta endogamia y la formación de dinastías; el nepotismo también se halla presente. Desde un punto de vista geográfico, los canónigos suelen proceder de la propia diócesis o de la región donde se halla el cabildo correspondiente. La permanencia en la prebenda es larga y, en cuanto a la formación académica, un buen porcentaje tiene algún grado de formación universitaria.

Los casos estudiados hasta la fecha no agotan el tema porque en la España moderna el número de cabildos y de capitulares es abundante y, sin duda, si se profundiza en el análisis se podrán introducir matizaciones y observar comportamientos diversos. Sobre todo queda por ver el caso de los pequeños capítulos ubicados en ciudades de reducido tamaño. Para el caso concreto de los cabildos aragoneses no disponemos de estudios que nos informen sobre el clero capitular. Por ello, en este trabajo, me propongo mostrar quiénes eran los canónigos de las catedrales aragonesas en los años setenta del siglo XVIII utilizando una fuente no usada hasta la fecha.

\footnotetext{
14 A. Domínguez ORTIZ, op. cit., p. 39.

15 O. Rey CASTElaO, «El alto clero gallego en tiempos de Carlos III», Coloquio internacional sobre Carlos III y su siglo, Vol. 2, Madrid, 1990, pp. 579-600. R. SÁNCHEZ GonZÁLEZ, Iglesia y sociedad en la Castilla moderna. El cabildo catedralicio de la sede primada (siglo XVII), Toledo, 2000. A. Morgado García, «Vida de canónigo. Percepción, origen y status de vida del alto clero durante el Antiguo Régimen», en: F. J. ArAnda PÉRez, (Coord.), Sociedad y élites eclesiásticas en la España Moderna, Cuenca, 2000, pp. 77-100. L. J. CORONAS VIDA, «Los miembros del cabildo de la catedral de Jaén (1700-1737)», Chronica Nova, 15 (1986-1987), pp. 101-126. P. FATJó GómEZ, «Aproximación a una élite institucional de la Catalunya moderna: los capitulares de la seo de Barcelona en el siglo XVII», Pedralbes, 13-II (1993), pp. 149-162. A. Jordé FERNÁNDEZ, «Els canonges de la Seu de Tarragona durant el segle XVIII: aproximació al seu estudi», Església i societat a la Catalunya del segle XVIII, Cervera, 1990, pp. 255-265. R. MARín LóPEZ, El cabildo de la catedral de Granada en el siglo XVI, Granada, 1998.
} 
Como es sabido, la monarquía disponía de amplias competencias en la provisión de los altos cargos eclesiásticos de la iglesia española, razón por la cual era preciso disponer de datos sobre aquéllos clérigos que reunían los requisitos necesarios para ser promocionados a destinos superiores en la carrera eclesiástica. Por ello, y con la vista puesta en futuros nombramientos, se pedían informes sobre los clérigos más destacados de las diócesis. En el caso que nos ocupa se trata de los remitidos por los obispos aragoneses al confesor del rey Joaquín de Cleta, arzobispo de Thebas, en 1772, 1774 y 1775. A los prelados de Aragón, como a los de otras diócesis, se les piden datos sobre la edad, naturaleza, literatura, escuela y circunstancias de los clérigos más destacados de sus respectivas diócesis, aunque los prelados no siempre se ciñen con exactitud al cuestionario sino que interpretan a su manera la forma de hacer el informe. Los obispos enviarán noticias sobre las dignidades, canónigos, bajo clero catedralicio y, ocasionalmente, referencias sobre los que consideran clérigos más destacados de la diócesis, aunque no formen parte del clero catedralicio. En alguna diócesis, como es el caso de Zaragoza, el prelado evita informar de algunos individuos, aunque sean de mérito, por ser demasiado mayores o estar enfermos ${ }^{16}$.

Además de los informes remitidos por los obispos existen otros, salvo en el caso de Barbastro, sin fecha ni firma, pero que se refieren a los mismos canónigos en la mayor parte de las diócesis, mientras en otras estos informes anónimos añaden algunos clérigos no presentes en los elaborados por los obispos; por ello aparecen en algunos cabildos un número de capitulares superior al de la nómina habitual de las catedrales aragonesas. Los informes anónimos, por tanto, son de fechas cercanas a los redactados por los prelados y pueden haber sido confeccionados en la Corte. Son documentos bastante asépticos, que presentan, a veces, un contraste evidente en la valoración de las cualidades personales de determinados canónigos con el redactado por el respectivo obispo. El caso más llamativo es el del cabildo de Albarracín, donde el prelado vierte duras acusaciones contra algunos capitulares, mientras que el informe anónimo se expresa elogiosamente o nada dice sobre su conducta ${ }^{17}$. También, ocasionalmente, ambos informes dan edades y nombres de pila distintos del mismo individuo.

La información aportada por los dos informes se refiere a 158 dignidades y canónigos ${ }^{18}$, un número superior al de la nómina teórica de las catedrales arago-

${ }^{16}$ AHN, Estado, Leg. 2.857-2.

${ }^{17}$ Los obispos que emiten los informes son José Molina Lario y Navarro (Albarracín), Juan Manuel Cornel (Barbastro), Antonio Sánchez Sardinero (Huesca), Pascual López Estaún (Jaca), José Laplana y Castellón (Tarazona), Francisco José Rodríguez Chico (Teruel) y Juan Sánchez de Buruaga (Zaragoza).

${ }^{18}$ En realidad son 157 individuos, pues un canónigo de Huesca pasó a Tarazona, por lo que está contabilizado dos veces.

Hispania Sacra, LXI

124, julio-diciembre 2009, 545-569, ISSN: 0018-215-X 
nesas. Además de suministrar datos sobre los capitulares, los obispos remiten información sobre los clérigos que consideran con más méritos para acceder a puestos superiores. Se dispone así de noticias sobre 217 clérigos que ejercen su tarea en las catedrales, en alguna colegiata o en parroquias, aunque el análisis de este clero lo abordaré en otra ocasión, para centrarme ahora únicamente en los canónigos y dignidades.

La primera cuestión que cabe decir sobre los canónigos aragoneses en ejercicio durante los años setenta del siglo XVIII es que se trata de un clero con una edad media alta, 51 años, que ofrece una escasa dispersión, pues oscila entre los 47 años de los canónigos turolenses y turiasonenses y los 56 de los jacetanos (Cuadro 1). Respecto a la edad, no obstante, cabe precisar que con alguna frecuencia el informe del obispo y el anónimo ofrecen datos contradictorios, adjudicando distintas edades a los mismos individuos. En tales casos se ha optado por dar como edad la media de ambos informes, cuestión que no altera el resultado medio porque es habitual que las diferencias sean escasas. La edad media es mayor que la observada por Irigoyen para los canónigos de Murcia en 1592, pues allí es de sólo 40 años ${ }^{19}$; para el resto de lo cabildos españoles sólo se dispone de datos sobre la edad en el momento del ingreso.

\section{Cuadro 1 \\ Edad media de los canónigos aragoneses}

\begin{tabular}{|l|c|}
\hline Albarracín & 53 \\
\hline Barbastro & \\
\hline Huesca & 49 \\
\hline Jaca & 56 \\
\hline Tarazona & 47 \\
\hline Teruel & 47 \\
\hline Zaragoza & 53 \\
\hline Aragón & $\mathbf{5 1}$ \\
\hline
\end{tabular}

Los datos sobre los años de permanencia en sus canonicatos de los capitulares aragoneses se limitan a las catedrales de Albarracín, Barbastro y Tarazona, mostrando en los dos primeros casos una media de 17 y 14 años respectivamente, es decir que podemos hablar de una permanencia larga y, en consecuencia,

19 A. IRIGOYEN LóPEZ, Entre el cielo y la tierra. Entre la familia y la institución. El cabildo de la catedral de Murcia en el siglo XVII, Murcia, 2000, p. 83. 
de una escasa promoción hacia puestos superiores (Cuadro 2). En Tarazona el período medio de permanencia baja a 8 años, sin duda porque existen 10 canónigos que llevan menos de 5 años. Algunos capitulares, tres en cada catedral, llevan más de 20 años en sus puestos. La larga permanencia en la prebenda, incluso más acusada que en Aragón, es una característica que también se da en Santiago de Compostela y en Murcia ${ }^{20}$.

\section{Cuadro 2}

Años de residencia de los canónigos aragoneses

\begin{tabular}{|l|c|c|c|c|}
\hline & < de 5 & De 5 a 20 & > de 20 & Media \\
\hline Albarracín & & 9 & 3 & 17 \\
\hline Barbastro & 2 & 6 & 3 & 14 \\
\hline Tarazona & 10 & 10 & 3 & 8 \\
\hline
\end{tabular}

La procedencia geográfica de los canónigos se desconoce, salvo en los casos de las diócesis de Albarracín y Tarazona (Cuadro 3). En Albarracín casi la mitad proceden de la propia diócesis y el resto de Aragón, salvo tres cuyo origen es desconocido. En Tarazona se detecta la existencia de un mayor número, casi un 25 por ciento, de capitulares originarios de espacios distintos al diocesano o al aragonés. Se advierte la presencia de cuatro catalanes introducidos por el obispo Vilanova, tres castellanos, uno de Logroño y otro de Soria. Aparece, por tanto, como un cabildo más abierto al exterior que el de Albarracín.

Esta situación es bastante similar a la de otros capítulos españoles, donde se puede apreciar que predominan los capitulares procedentes de las propias diócesis o de la región. Así, en Córdoba el 75\% proceden de Andalucía, en Jaén la mayoría son andaluces, en Santiago de Compostela son gallegos el 54\% antes del concordato de 1753 y el 65\% después de él, en Cádiz el 67\% son de la diócesis y también predominan los catalanes en los cabildos de Tarragona y Barcelona. Los canónigos y dignidades de Murcia en el siglo XVII procedentes de la propia diócesis se elevan al $71 \%$, aunque este porcentaje baja al $44 \%$ en la siguiente centuria; esta proporción baja radicalmente cuando se trata de las canonjías de oficio, que se obtienen por oposición, donde sólo el 7,6\% son de la diócesis ${ }^{21}$.

20 O. Rey Castelao, op . cit, p. 589. A. CÁnovas Botía, Auge y decadencia de una institución eclesial: el cabildo de Murcia en el siglo XVIII. Iglesia y sociedad, Murcia, 1994, pp. 277-279.

${ }^{21}$ R. VÁzQuez Lesmes, Córdoba y su cabildo catedralicio, Córdoba, 1987, pp. 89-92. A. MorGADO GARCíA, Iglesia y sociedad en el Cádiz del siglo XVIII, Cádiz, 1989, p. 97 y «Vida de canónigo...» op. cit., p. 84. L. J. CORONAS VIDA, op. cit., pp. 108-110. O. REY CASTELAO, op . cit., p. 586. A. IRIGOYEN LóPEZ, op. cit., p. 228. A. CÁNOVAs Botía, op. cit., pp. 268-271.

Hispania Sacra, LXI

124, julio-diciembre 2009, 545-569, ISSN: 0018-215-X 
Cuadro 3

Origen geográfico de los canónigos aragoneses

\begin{tabular}{|l|c|c|c|c|c|c|c|c|}
\hline & Diócesis & $\mathbf{\%}$ & Aragón & $\mathbf{\%}$ & Otros & \% & Sin datos & \% \\
\hline Albarracín & 6 & 42,9 & 5 & 35,7 & & & 3 & 21,4 \\
\hline Barbastro & & & & & & & 13 & 100 \\
\hline Huesca & & & & & 1 & 3,1 & 31 & 96,9 \\
\hline Jaca & & & & & & & 19 & 100 \\
\hline Tarazona & 9 & 24,3 & 17 & 46,0 & 9 & 24,3 & 2 & 5,4 \\
\hline Teruel & & & & & & & 19 & 100 \\
\hline Zaragoza & & & & & 2 & 8,3 & 22 & 91,7 \\
\hline Aragón & $\mathbf{1 5}$ & $\mathbf{9 , 5}$ & $\mathbf{2 2}$ & $\mathbf{1 3 , 9}$ & $\mathbf{1 2}$ & $\mathbf{7 , 6}$ & $\mathbf{1 0 9}$ & $\mathbf{6 9 , 0}$ \\
\hline
\end{tabular}

Con respecto al origen familiar, cabe decir que en la mayor parte de los casos, 121 de 158 (76,6\%), se carece de información (Cuadro 4). La ausencia de datos es total para Barbastro y Jaca, mientras que en las demás catedrales se aportan noticias sólo sobre algunos capitulares. Cuando se nos manifiestan orígenes familiares apreciamos que se habla de nobles en 19 casos, mientras que para referirse a otras familias se usan calificativos tales como distinguida, honesta, condecorada, antigua, principal o ilustre. En un único caso se destaca que un canónigo de Zaragoza es de origen humilde. Todo esto puede estar indicando que los obispos sólo reflejaron orígenes familiares cuando éstos tenían algo de destacable, algo que pudiera hacerlos distintos, tanto por la parte alta de la escala social como por la baja.

Si el razonamiento es correcto, tendríamos un origen familiar mayoritariamente común, intermedio, sin una especial relevancia social. Esto acercaría los cabildos aragoneses a la situación de otros como Granada, Murcia, en el siglo XVII, y Tarragona, donde predominan los capitulares de extracción social intermedia 22 . Por el contrario, en otros cabildos, como Palencia, Jaén, Murcia, en el siglo XVIII, o Toledo, se ha detectado una presencia importante

${ }^{22}$ En Granada los procedentes de la nobleza son muy escasos y existe un cabildo «... integrado por individuos de extracción social intermedia, procedentes en su mayoría de familias hidalgas, funcionarios reales o judiciales, y con el paso del tiempo por individuos emparentados o extraídos de la propia iglesia...»; R. MARín LóPEZ, op. cit., pp. 151-155. En la Murcia del XVII las familias de la oligarquía no mostraron gran interés en ocupar puestos en el cabildo y sólo una quinta parte de los linajes murcianos aparece entre los capitulares; A. IRIGOYEN LóPEZ, op . cit., pp. 172-175 y 202. Para el cabildo de Tarragona, una pequeña muestra indica que hay 3 canónigos de familia noble, 4 hijos de mercaderes, 1 hijo de cirujano, 1 hijo de apotecario, 7 hijos de doctores en derecho y 11 de familias campesinas; A. JORDÁ FERNÁNDEZ, op. cit., p. 259. 


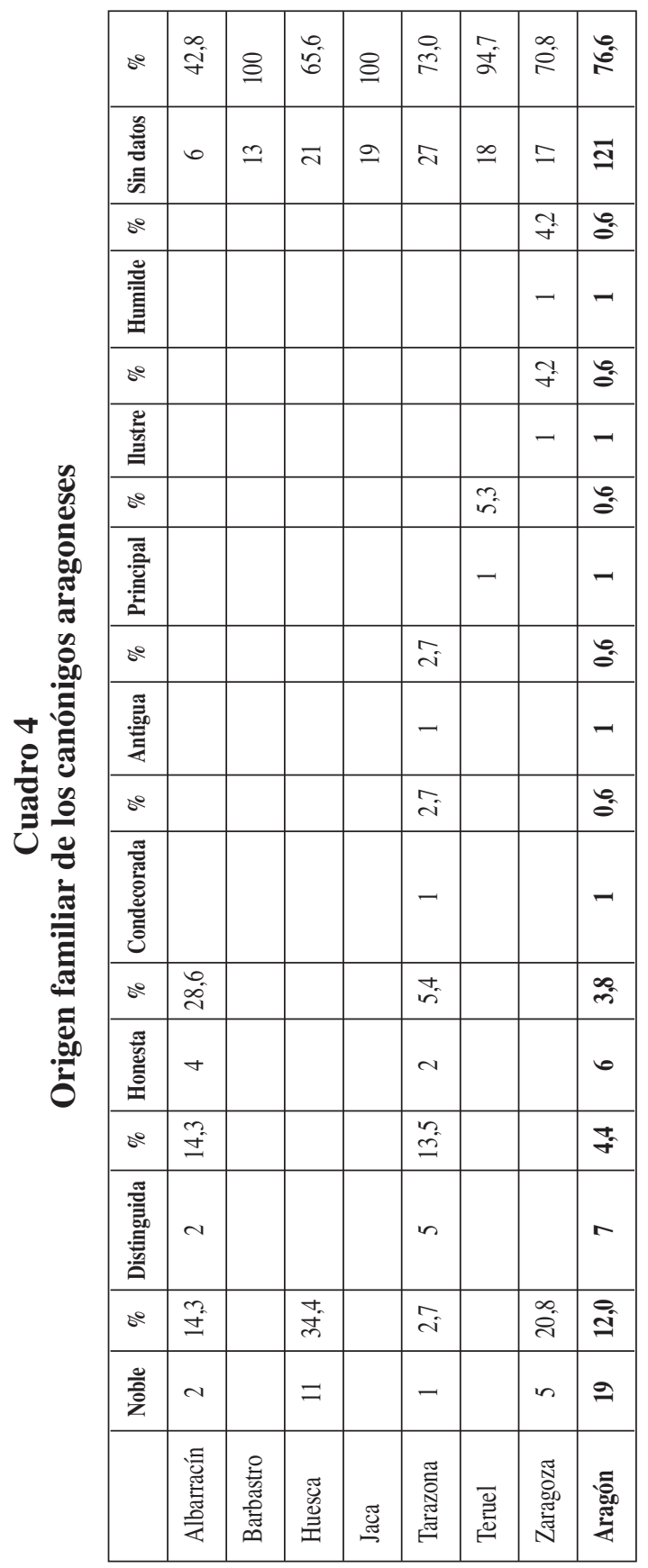

Hispania Sacra, LXI

124, julio-diciembre 2009, 545-569, ISSN: 0018-215-X 
de nobles ${ }^{23}$. Esto nos habla de que pueden darse distintas situaciones en las catedrales españolas y de que es preciso afinar más en la cuestión de la extracción social de estos clérigos.

Un aspecto importante es el nivel formativo de estas personas. Se puede apreciar que el $38 \%$ son doctores, mientras que otro $28,5 \%$ tiene algún grado de formación universitaria, es decir un $66,5 \%$ ha pasado por la universidad, con mayor o menor grado de aprovechamiento ${ }^{24}$. El 5\% tiene estudios que podríamos calificar de elementales ${ }^{25}$, es decir, no tiene otra instrucción que la básica (Cuadro 5). Por tanto cabe afirmar que su nivel de formación es, en líneas generales, alto. Los canónigos mejor preparados académicamente se encuentran en Huesca, Tarazona y Zaragoza, probablemente porque estos cabildos eran más importantes y para acceder a ellos seguramente había más competencia y también por haber centros universitarios en la ciudad, como sucede en Huesca y Zaragoza. El obispo de Jaca se lamenta de la falta de centros de formación en su diócesis, a lo que achaca el bajo nivel formativo de los clérigos bajo su tutela ${ }^{26}$. Sin duda diócesis pequeñas

23 «Por lo que se refiere a su procedencia social, la vinculación con los notables locales y con los grupos mesonobiliarios es un hecho constatado universalmente: en Jaén casi las tres cuartas partes de los prebendados son de origen nobiliario (y los plebeyos, en su inmensa mayoría, no pasan de racioneros, el estrato inferior del cuerpo capitular). En Córdoba la proporción supera el $80 \%$, con un fuerte predominio de la baja nobleza, aunque las raciones y medias raciones presentan una proporción más elevada de plebeyos y de los canonicatos solamente acceden a los de oficio, lo que revela que de cuando en cuando triunfaban las virtudes intelectuales y morales sobre la sangre. En Tarragona los prebendados en su mayor parte proceden de casa acomodadas de campesinos propietarios, comerciantes, artesanos, abogados e incluso de la nobleza. En Barcelona el porcentaje nobiliario es también muy fuerte: más de la mitad de los capitulares de los que se conoce la procedencia social, aunque también encontramos hijos de artesanos, mercaderes y labradores»; A. Morgado García, «Vida de canónigo...»op. cit., p. 85 y «El alto clero gaditano durante el Antiguo Régimen (1600-1833)», Studia Histórica. Historia Moderna, 16 (1997), p. 231. A. CABEZA, Clérigos y señores. Política y religión en Palencia en el Siglo de Oro, Palencia, 1996, pp. 251 y ss. L. J. CORONAS VidA, op. cit., pp. 102-103. A. CÁnOvas Botía, op. cit., p. 282. R. SÁNCHEZ GONZÁLEZ, op. cit., p. 31.

${ }^{24}$ En el cuadro 5, columna «universidad», se anotan aquellos canónigos que parecen haber pasado por alguna Universidad, aunque su grado de formación nos sea desconocido; incluyo a los canónigos en cuyos informes se anotan expresiones tales como canonista, colegial, estudió filosofía, estudió cánones, teólogo, estudió teología y leyes, estudia jurisprudencia...

25 En «otros estudios» incluyo a los canónigos cuyos informes se refieren a su grado de formación con expresiones como estudios para ordenarse, poca literatura, algo de leyes, buen gramático, sólo la gramática o de literatura mediana. Obviamente, son expresiones difusas, al igual que las que se refieren a los agrupados en la columna «universidad», lo que puede conducir a errores individuales; sin embargo, creo que el cuadro general queda bastante claro.

26 «La falta de universidad y de estudio público trae consigo el no labrarse profundamente sujetos con la enseñanza de facultades mayores ni estudiantes en su estudio y assí son pocos los que se proponen. Las casas religiosas, que son corto número, están sin estudios. Los capítulos eclesiásticos seculares son también pocos y de cortas rentas, por lo que sus individuos no pasan comúnmente de la suficiencia para el estado sacerdotal y para confesores algunos. De los curas existen algunos que siguieron fuera de la diócesis curso entero escolástico y se hicieron especialmente hábiles para el ministerio que ejercen». Informe del obispo de Jaca (14-04-1774); AHN, Estado, Leg. 2.857-2. 
como Jaca, Albarracín, Barbastro o Teruel, nacidas tras la reorganización eclesiástica emprendida por Felipe II, tenían serias limitaciones para mantener centros educativos eclesiásticos de cierto nivel y tampoco disponían de instituciones «civiles» de formación superior que pudieran paliar esa carencia. El nivel de formación de los capitulares de Huesca, Tarazona y Zaragoza podemos calificarlo de alto si lo comparamos con otros cabildos españoles, mientras que en los demás casos se sitúan por debajo de una hipotética media ${ }^{27}$.

\section{Cuadro 5}

Nivel de formación de los canónigos aragoneses

\begin{tabular}{|l|c|c|c|c|c|c|c|c|c|c|}
\hline & Doctor & $\%$ & Universidad* & $\%$ & $\begin{array}{c}\text { Otros } \\
\text { estudios }\end{array}$ & $\%$ & $\begin{array}{c}\text { Sin } \\
\text { carrera }\end{array}$ & \% & $\begin{array}{c}\text { Sin } \\
\text { datos }\end{array}$ & \% \\
\hline Albarracín & & & 7 & 50 & & & 1 & 7,1 & 6 & 42,9 \\
\hline Barbastro & 2 & 15,4 & & & 3 & 23,1 & 2 & 15,4 & 6 & 46,2 \\
\hline Huesca & 22 & 68,8 & 5 & 15,6 & 3 & 9,4 & & & 2 & 6,3 \\
\hline Jaca & 6 & 31,6 & 6 & 31,6 & 1 & 5,3 & 1 & 5,3 & 5 & 26,3 \\
\hline Tarazona & 20 & 54,0 & 5 & 13,5 & & & & & 12 & 32,4 \\
\hline Teruel & & & 9 & 47,4 & & & 4 & 21,1 & 6 & 31,6 \\
\hline Zaragoza & 10 & 41,7 & 13 & 54,2 & 1 & 4,2 & & & & \\
\hline Aragón & $\mathbf{6 0}$ & $\mathbf{3 8 , 0}$ & $\mathbf{4 5}$ & $\mathbf{2 8 , 5}$ & $\mathbf{8}$ & $\mathbf{5 , 0}$ & $\mathbf{8}$ & $\mathbf{5 , 0}$ & $\mathbf{3 7}$ & $\mathbf{2 3 , 4}$ \\
\hline
\end{tabular}

* Estudios universitarios sin concretar

De las universidades donde cursaron sus estudios, se dispone de datos sólo para la mitad de los individuos (Cuadro 6). En los casos donde se conoce la universidad de formación se aprecia que Huesca ocupa el lugar principal, pues más de la mitad estudiaron allí. Le siguen en importancia Zaragoza y Alcalá, con 10 y 8 canónigos respectivamente. Otras universidades nacionales que aparecen son Gandía, Oviedo y Valladolid. De las extranjeras, solamente consta que dos capitulares estudiaron en Bolonia. Por tanto, predomina la formación en las universidades del entorno geográfico más cercano, salvo excepciones, y sólo diez se formaron en universidades prestigiosas ${ }^{28}$.

27 A. CÁnovas Botía, op. cit., pp. 285-286. A. Morgado García, «El alto clero gaditano...»op. cit., p. 231 y «Vida de canónigo...»op. cit., p. 86. O. ReY CASTELAO, op. cit., p. 589. A. JORDÀ FERNÁNDEZ, op. cit., p. 259. L. J. CORONAS VIDA, op. cit., p. 116.

${ }^{28}$ En este caso, la comparación sólo puede establecerse con Jaén, donde de 42 casos conocidos 12 estudiaron en Salamanca, 15 en Baeza y 12 en Granada: L. J. CoRONAS VIDA, op. cit., p. 116.

Hispania Sacra, LXI

124, julio-diciembre 2009, 545-569, ISSN: 0018-215-X 


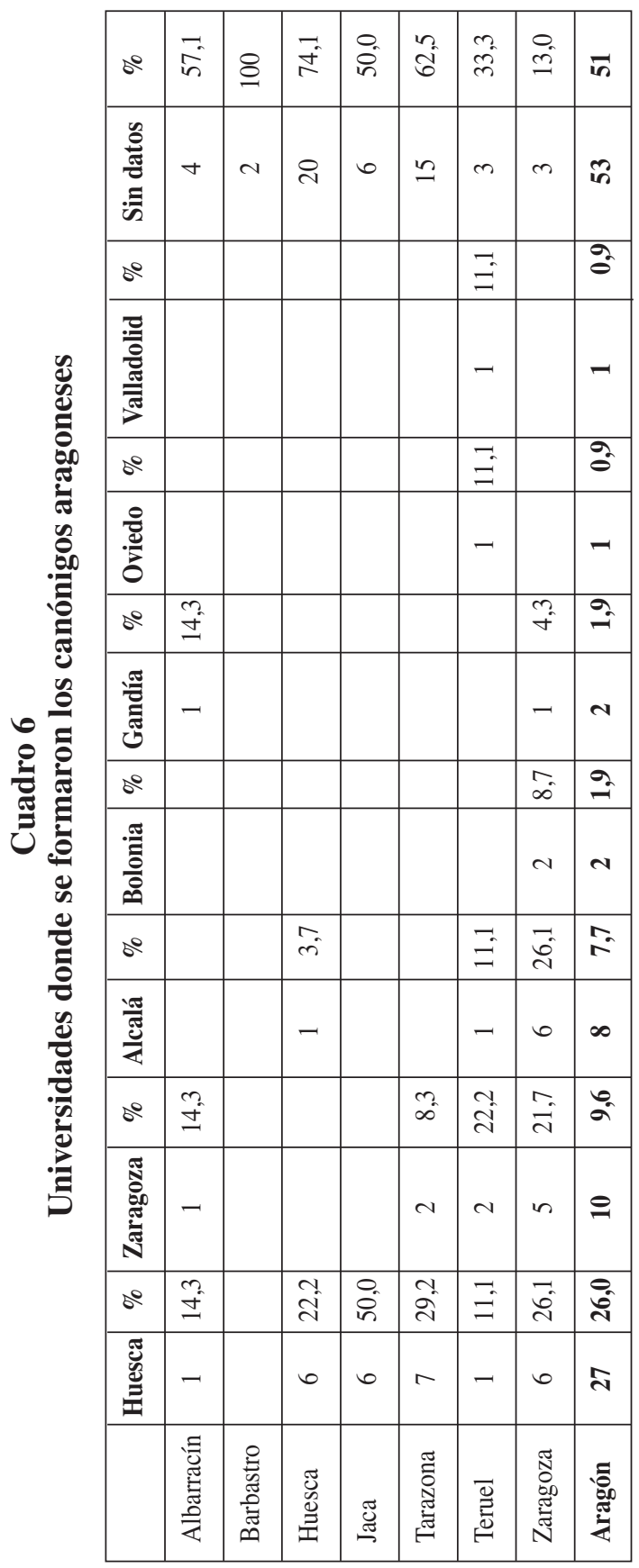


Los informes prestan atención a la orientación teológica de los canónigos y se distingue entre tomistas, suaristas y afectos a los jesuitas, aspecto este que parece interesar especialmente (Cuadro 7). No obstante, sólo se informa de la tendencia teológica en el caso de 64 individuos, lo que supone un 40,5\% de los capitulares. Predominan los tomistas, son 32, seguidos de los suaristas, que son quince. Los canónigos afectos a los jesuitas son 17 y se concentran casi todos en Zaragoza, salvo dos turiasonenses.

\section{Cuadro 7}

Escuela teológica de los canónigos aragoneses

\begin{tabular}{|l|c|r|c|c|c|c|c|c|}
\hline & Tomista & $\mathbf{\%}$ & Suarista & $\mathbf{\%}$ & Jesuitas & \% & Sin datos & \% \\
\hline Albarracín & 7 & 50,0 & 4 & 28,6 & & & 3 & 21,4 \\
\hline Barbastro & & & & & & & 13 & 100 \\
\hline Huesca & 3 & 9,4 & 6 & 18,8 & & & 23 & 71,8 \\
\hline Jaca & 9 & 47,4 & & & & & 10 & 52,6 \\
\hline Tarazona & 2 & 5,4 & 3 & 8,1 & 2 & 5,4 & 30 & 81,0 \\
\hline Teruel & 2 & 10,5 & 2 & 10,5 & & & 15 & 78,9 \\
\hline Zaragoza & 9 & 37,5 & & & 15 & 62,5 & & \\
\hline Aragón & $\mathbf{3 2}$ & $\mathbf{2 0 , 2 5}$ & $\mathbf{1 5}$ & $\mathbf{9 , 4 9}$ & $\mathbf{1 7}$ & $\mathbf{1 0 , 7 5}$ & $\mathbf{9 4}$ & $\mathbf{5 9 , 4 9}$ \\
\hline
\end{tabular}

Una cuestión importante es la relativa a los sistemas de acceso, a la forma de ingresar en los cabildos. Morgado ha señalado que «el reclutamiento de cualquier cabildo catedralicio del Antiguo Régimen estuvo fuertemente determinado por las relaciones clientelares: obispos aupando a miembros de su «familia», prebendados que, usando de coadjutorías, resignas, dimisiones o permutas, consiguen un heredero de su elección, municipios usando de recomendaciones, ruegos o pleitos, opositores con vinculaciones colegiales, universitarias o familiares con alguien del tribunal...», lo que da como resultado «la patrimonialización de las prebendas» ${ }^{29}$. Se forman en algunos capítulos auténticos clanes familiares, como puede apreciarse en Cádiz, Gerona o Jaén ${ }^{30}$.

El acceso a los canonicatos se producía por distintas vías, al margen del sistema de oposición previsto para las cuatro canonjías de oficio: doctoral, magis-

${ }^{29}$ A. Morgado García, «Vida de canónigo...» op. cit., pp. 83-84 y ss.

30 A. Morgado García, «El alto clero gaditano...» op. cit., p. 229. M. JimÉNEZ SuredA, L'Església catalana sota la monarquia dels Borbons: la catedral de Girona en el segle XVIII, Girona, 1999, pp. 261-349. L. J. CORONAS VIDA, op. cit., pp. 106-108.

Hispania Sacra, LXI

124, julio-diciembre 2009, 545-569, ISSN: 0018-215-X 
tral, penitenciario y lectoral ${ }^{31}$. Los informes manejados aportan pocos datos, pues únicamente dejan claro el método de ingreso en 42 ocasiones, además de los 34 casos que por ocupar canonjías de oficio sabemos que accedieron por oposición. La carencia de información es total para 82 canónigos, es decir más de la mitad de los capitulares (Cuadro 8).

El sistema de coadjutoría consistía en que «... cuando un canónigo estaba enfermo o había llegado a una edad en la que no podía atender a sus obligaciones se le permitía nombrar un coadjutor, aunque tenía que ser aceptado por la Santa Sede. El coadjutor era ya miembro del cabildo y sucedería en la prebenda a su titular. Tenía la obligación de realizar todas las tareas que correspondían al asistido y que éste no pudiera llevar a cabo, pero sin cobrar la renta. La ventaja radicaba en tener la sucesión asegurada» ${ }^{32}$. Por este sistema accedieron nueve canónigos, una cifra muy pequeña comparada con la de otras catedrales españolas. Lo mismo sucede con el método de resigna, que «consistía en una especie de dimisión, pero en la que el dimisionario nombra a su sucesor. El resignante ponía en manos del Papa su prebenda y el Papa designaba para el puesto al que le pedía el saliente» ${ }^{33}$. Fue una fórmula frecuentemente usada en los cabildos estudiados hasta la fecha, pero muy minoritaria en Aragón, donde sólo encontramos un caso en Teruel ${ }^{34}$.

La mayoría de los canónigos, de los que conocemos la forma de acceder, lo fueron a propuesta del rey, de Roma o del obispo respectivo. Algunos de los prelados aprovechaban para situar a gente de su entorno o de su confianza en el cabildo de sus respectivas diócesis. Este es el caso del obispo Vilanova, de Tarazana, que otorgó canonjías a su mayordomo, José Alsina, y a su secretario, Francisco Sanz. El obispo Alcaraz, de la misma diócesis, hizo canónigo a su secretario. También hallamos situaciones mixtas, en las cuales se accede al canonicato por un método y luego se consigue alguna de las dignidades por otro pro-

${ }^{31}$ Magistral: Era experto en teología y predicador en la catedral de los sermones programados o de tabla y los extraordinarios; solía enseñar teología dogmática. Doctoral: Era perito en derecho canónico y encargado de defender al cabildo en sus bienes, derechos y prerrogativas, dirigir los negocios judiciales o extrajudiciales del mismo y emitir dictamen o parecer, verbal o escrito, en los asuntos jurídicos pertinentes; solía enseñar derecho canónico. Lectoral: Era biblista y se encargaba de explicar públicamente en la iglesia, en días y horas determinados, la Biblia o la doctrina católica; solía ser profesor de Sagrada Escritura. Penitenciario: Era confesor oficial de la catedral y docente de teología moral.

${ }^{32}$ L. J. CORONAS VIDA, op. cit., p. 105.

33 Idem.

${ }^{34}$ Las coadjutorías y resignas fueron abundantemente empleadas en Cádiz, Gerona, Jaén, Córdoba y Murcia: A. Morgado García, «El alto clero gaditano...» op . cit., M. JimÉnEz SUREDA, op. cit., L. J. Coronas Vida, op . cit., R. VÁzQuez Lesmes, op. cit., A. CÁnOvas Botía, op. cit. En el cabildo murciano, durante el siglo XVII, el 55\% de las dignidades y el $27 \%$ de los canónigos accedieron por coadjutoría o resigna; entre los canónigos, sin embargo, la mayoría (un 54\%) accedieron por oposición: A. IRIGOYEN LÓPEZ, op . cit., pp. 38-41. 


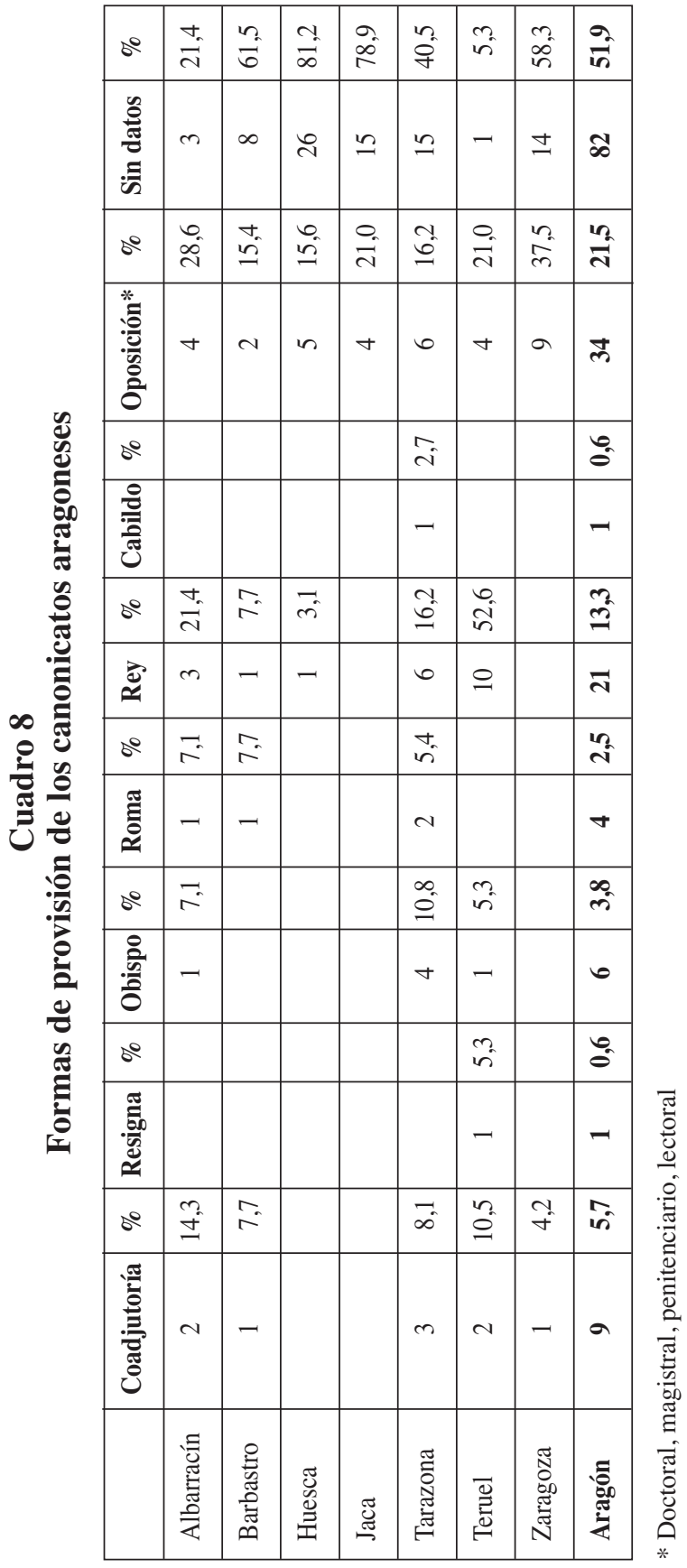

Hispania Sacra, LXI

124, julio-diciembre 2009, 545-569, ISSN: 0018-215-X 
cedimiento. Así encontramos un canónigo de Albarracín que lo fue por el papa, pero que luego pasó a chantre por provisión real, o un doctoral de Tarazona que más tarde fue deán por decisión real. Por el contrario, en Teruel, un capitular provisto por la realeza pasó posteriormente a la dignidad de tesorero por coadjutoría.

Las trayectorias profesionales previas al cargo de canónigo, o simultáneas al ejercicio del mismo, pueden seguirse, aunque sea someramente, en el $60 \%$ de los casos. Puede observarse en el Cuadro 9 que 17 clérigos (9\%) previamente ocuparon cargos en iglesias de menor rango, es decir que sirvieron en iglesias parroquiales o en colegiatas; es un número pequeño, que muestra como el servicio pastoral en las parroquias no era el método más efectivo para conseguir una canonjía. Más útil era servir al obispo o a la administración diocesana, en puestos tales como los de secretario del prelado, vicario general, examinador sinodal o visitador. Hasta 43 canónigos (23\%) ocuparon puestos de esta índole; es verdad, no obstante, que en algunos casos el desempeño de tareas administrativas en el obispado es simultáneo a su condición de capitular y que no siempre se puede precisar si se es canónigo por esta circunstancia o si se desempeña esa tarea por ser miembro del cabildo; con frecuencia parece tratarse de lo último. Sin embargo, como ya se ha visto, el servir al obispo puede ser un buen camino para obtener una canonjía ${ }^{35}$.

La promoción interna que supone pasar de una canonjía a otra mejor remunerada o a una dignidad, se aprecia en siete casos. También se observa como en los mejores cabildos, casos de Huesca, Zaragoza y Tarazona, aparecen canónigos que ya lo eran antes de otras catedrales, situación que no se da en los demás capítulos aragoneses, los cuales podrían ser considerados como de «primer escalón», del que sólo algunos lograban ascender a otro superior. Ese fue, por ejemplo, el caso de Luis Garcés, que se graduó en teología en la universidad de Huesca, fue magistral de Teruel, deán de Albarracín y finalmente magistral de Zaragoza. También en Huesca hallamos dos canónigos que antes lo eran de Jaca y Barbastro, mientras en Tarazona uno de ellos lo fue previamente en Huesca.

Si hacemos caso de las opiniones de los obispos, únicamente habría eclesiásticos dignos de mayores ascensos en Albarracín, uno, Barbastro, seis, Tarazona, tres, y Teruel, seis; son 16 canónigos de un total de 158 mencionados, lo cual nos da una muestra de las escasas posibilidades de promocionar que tenía este colectivo de clérigos. Esta misma situación de falta de promoción se da en Cádiz ${ }^{36}$, mientras en la ciudad de la Alhambra Marín López ${ }^{37}$ ha señalado que

35 En el cabildo murciano, durante el XVIII, un $10 \%$ de los prebendados contaban antes de serlo con servicios al obispo o a la diócesis y sólo un 2,5\% habían tenido cargos parroquiales; A. CÁNOVAS BotíA, op. cit., pp. 274-277.

${ }^{36}$ A. Morgado García, «El alto clero gaditano...» op. cit., p. 228.

${ }^{37}$ R. MARÍn LÓPEZ, op. cit., p. 154. 


\begin{tabular}{|c|c|c|c|c|c|c|c|c|c|}
\hline & $\therefore$ & $\overrightarrow{i n}$ & $\bar{n}$ & $\begin{array}{l}0 \\
\ddot{v}\end{array}$ & ţ. & $\begin{array}{l}0 \\
y\end{array}$ & $\hat{q}$ & O̊. & r্ \\
\hline & 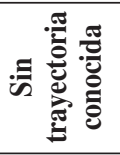 & $\infty$ & $\infty$ & 으 & $\infty$ & $\infty$ & $=$ & $a$ & $\mathfrak{N}$ \\
\hline & $b^{\circ}$ & & $\vec{\sigma}$ & 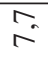 & & $\stackrel{n}{\sim}$ & $\exists$ & $\stackrel{0}{0}$ & हैे \\
\hline 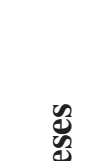 & 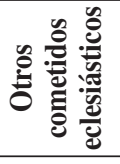 & & - & $m$ & & $m$ & $m$ & $m$ & 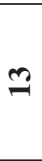 \\
\hline Е & $b^{\circ}$ & & & $\begin{array}{l}n \\
\infty \\
m\end{array}$ & $\begin{array}{l}0 \\
\stackrel{2}{2}\end{array}$ & $\begin{array}{l}0 \\
\text { in }\end{array}$ & & $\stackrel{m}{m}$ & בे \\
\hline 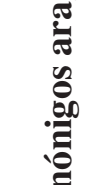 & 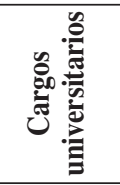 & & & $\cong$ & $m$ & $N$ & & 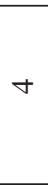 & $\stackrel{\mathbb{N}}{\mathbf{H}}$ \\
\hline త్ & $b^{\circ}$ & & & $\stackrel{\infty}{\sim}$ & & & & $\begin{array}{l}0 \\
0 \\
0\end{array}$ & 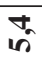 \\
\hline 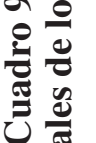 & 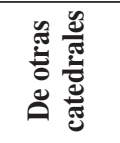 & & & in & & & & in & $\stackrel{ }{ }$ \\
\hline 产 & $b^{\circ}$ & $\bar{r}$ & $\stackrel{m}{ \pm}$ & & & & $\underset{r}{\stackrel{\nabla}{r}}$ & $\hat{6}$ & $\stackrel{\infty}{\infty}$ \\
\hline 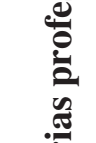 & 冾 & - & $\sim$ & & & & $N$ & $N$ & n \\
\hline อี & $\delta^{\circ}$ & $\begin{array}{l}m \\
\pm\end{array}$ & $\begin{array}{l}m \\
\dot{J}\end{array}$ & $\stackrel{3}{0}$ & $\hat{\tilde{f}}$ & $\frac{n}{n}$ & $\begin{array}{l}\text { ה̃ } \\
\text { ה }\end{array}$ & $\hat{6}$ & ले \\
\hline 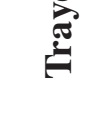 & 递高 & $N$ & $N$ & $\nabla$ & $a$ & $n$ & 0 & in & $\mathscr{P}$ \\
\hline & $\Delta^{\circ}$ & $\stackrel{\vec{i}}{\vec{i}}$ & $\vec{r}$ & $\vec{n}$ & $\vec{a}$ & $\begin{array}{l}0 \\
i n\end{array}$ & $\stackrel{\infty}{\infty}$ & $\hat{6}$ & $\bar{a}$ \\
\hline & 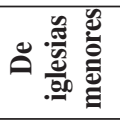 & $m$ & - & $N$ & $N$ & $\sim$ & in & $N$ & 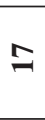 \\
\hline & & 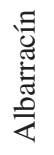 & 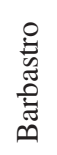 & 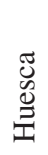 & 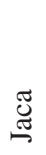 & 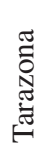 & 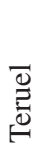 & 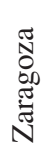 & 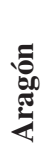 \\
\hline
\end{tabular}

Hispania Sacra, LXI

124, julio-diciembre 2009, 545-569, ISSN: 0018-215-X 
«... muchos capitulares continuaron una larga carrera eclesiástica fuera de Granada...» y en Murcia se constata que los canónigos de oficio, gracias a su preparación y relaciones, fueron los que accedieron con mayor frecuencia a mitras episcopales ${ }^{38}$.

Algunos canónigos, salvo en las catedrales de Albarracín y Jaca, desempeñan, además de su canonjía, otros cometidos eclesiásticos, como pueden ser el de confesor de monjas, abogado en los tribunales eclesiásticos, auditor de la Rota, inquisidor, consultor del Santo Oficio o capellán militar.

Por último, cabe destacar que 24 canónigos (13\%) desempeñan o han desempeñado puestos de profesor universitario. El caso más evidente es el de Huesca, donde hasta quince son o han sido profesores de la universidad. Esto es debido a la existencia de universidad en Huesca y al hecho de que está estrechamente vinculada al cabildo, por lo que fue frecuente que una parte de los profesores fuesen miembros del cabildo de la catedral ${ }^{39}$. En Zaragoza hay cuatro canónigos vinculados a la universidad en algún momento de su vida. Finalmente, tres canónigos de Jaca y dos de Tarazona fueron previamente profesores de universidad.

Los informes prestan atención a la conducta observada por los eclesiásticos y se observa que mayoritariamente (60\%) esta es buena, sólo en cinco casos se aprecia como regular y en tres como mala (Cuadro 10). En 46 casos (29\%) no se nos dice nada sobre la conducta, lo cual podría interpretarse como que no merece atención especial, que está dentro de la normalidad. Mención especial merecen ocho casos - seis en Albarracín y dos en Tarazona- en los que la opinión del obispo es contradictoria con la que expresa el informe anónimo, razón por la cual se colocan en una columna especial del cuadro (Buena/Mala). A la vista del cuadro 10 puede afirmarse que los casos de comportamiento más censurable se concentran en Albarracín. Las relaciones de los capitulares con el obispo parecen no ser buenas y ello pudo influir en la opinión negativa que el prelado expresa sobre siete capitulares, aunque algunas de las afirmaciones sobre la conducta de esos canónigos parecen fundadas y muestran un grupo de eclesiásticos de costumbres algo rudas.

El obispo acusa a varios clérigos de acudir a una representación de comedias a pesar de saber que no le gustaba al prelado. En el caso del canónigo La Cerda -nacido en Albarracín, en torno a 28 años de edad, de origen noble y promovido a la canonjía por el rey-, el obispo afirma que causa murmuración y escándalo su trato con mujeres y que siguió a una comedianta hasta otro pueblo, además de presentarlo como aficionado a los juegos prohibidos de cartas. Respecto

\footnotetext{
38 A. IRIGOYen LÓPEZ, op. cit., pp. 244-245.

${ }^{39}$ A. Durán Gudiol, «Notas para la historia de la Universidad de Huesca en el siglo XVI», Hispania Sacra, 21 (1968), pp. 87-154.
} 
al canónigo Alonso Texadillos, natural de Pozondón, un pueblo del obispado, el obispo afirma que fue visto con dos pistolas al cinto, una escopeta larga al brazo y un recipiente con pólvora, además de defender públicamente ante el cabildo su derecho a portar armas, atendiendo a su condición de eclesiástico, canónigo y noble. En sus tesis sobre el uso de las armas fue apoyado por varios capitulares $^{40}$, lo que parece indicar que una parte de los canónigos tenían la caza como una de sus actividades para entretener los ratos de ocio. El obispo también acusa a este grupo de falta de interés por los sermones, aunque los predique el mismo. En suma, parece tratarse de un grupo que no mantiene buenas relaciones con el obispo, lo que pudo influir en su opinión, pero cuya conducta podríamos calificar al menos de un tanto ruda y alejada del modelo teórico del buen eclesiástico. Se trata de sujetos con un nivel formativo bajo, salvo el doctoral, y proceden, excepto uno, de buenas familias de la tierra. A la vista del informe cabe afirmar que el cabildo de Albarracín era, de todos los aragoneses, el que reunía los canónigos con la peor conducta y sus capitulares son una excepción dentro de un grupo eclesiástico cuyo comportamiento es generalmente bueno.

\section{Cuadro 10}

Conducta de los canónigos aragoneses

\begin{tabular}{|l|c|c|c|c|c|c|c|c|c|c|}
\hline & Buena & $\boldsymbol{\%}$ & Regular & $\mathbf{\%}$ & Mala & $\boldsymbol{\%}$ & $\begin{array}{c}\text { Buena/ } \\
\text { Mala }\end{array}$ & \% & $\begin{array}{c}\text { Sin } \\
\text { datos }\end{array}$ & \% \\
\hline Albarracín & 6 & 42,9 & 1 & 7,1 & 1 & 7,1 & 6 & 42,9 & & \\
\hline Barbastro & 10 & 76,9 & 2 & 15,4 & & & & & 1 & 7,7 \\
\hline Huesca & 22 & 68,8 & 1 & 3,1 & 1 & 3,1 & & & 8 & 25,0 \\
\hline Jaca & 7 & 36,8 & & & & & & & 12 & 63,1 \\
\hline Tarazona & 29 & 78,4 & 1 & 2,7 & 1 & 2,7 & 2 & 5,4 & 4 & 10,8 \\
\hline Teruel & 5 & 26,3 & & & & & & & 14 & 73,7 \\
\hline Zaragoza & 17 & 70,8 & & & & & & & 7 & 29,2 \\
\hline Aragón & $\mathbf{9 6}$ & $\mathbf{6 0 , 8}$ & $\mathbf{5}$ & $\mathbf{3 , 2}$ & $\mathbf{3}$ & $\mathbf{1 , 8}$ & $\mathbf{8}$ & $\mathbf{5 , 1}$ & $\mathbf{4 6}$ & $\mathbf{2 9 , 1}$ \\
\hline
\end{tabular}

De lo expuesto se puede concluir que en Aragón existen unos cabildos de primera, como son Zaragoza, Huesca y, en menor medida, Tarazona, y otros con un nivel menor, que son los de Jaca, Barbastro, Teruel y Albarracín; tal di-

${ }^{40}$ Ciprián, hijo de una antigua familia de Teruel, López Garrido, de antigua familia de Bronchales, un pueblo del obispado, Juan Navarro y Toyuela, hijo de una familia noble de Albarracín, Pérez, procedente de una honesta familia de Biel (Zaragoza).

Hispania Sacra, LXI

124, julio-diciembre 2009, 545-569, ISSN: 0018-215-X 
visión puede establecerse en función del nivel formativo de sus miembros y de las trayectorias de algunos canónigos, que comienzan en los segundos y finalizan en los primeros.

En Aragón se observan diferencias con respecto a otros cabildos españoles, como la menor presencia de canónigos de origen noble o principal y un acceso a las prebendas no tan controlado localmente como en otros lugares, aunque será preciso contrastar los datos aquí expuestos con los aportados por estudios diacrónicos, que vayan más allá de la instantánea aquí mostrada.

Los canónigos aragoneses tienen una edad media de 51 años, una cuarta parte proceden de su diócesis o del resto de Aragón, la mayoría tienen formación universitaria $(66,5 \%)$-una buena parte de ellos la ha alcanzado en las universidades aragonesas $(35,6 \%)$ - y su conducta es mayoritariamente buena, sin perjuicio de la existencia de algunos comportamientos inadecuados.

Finalmente, cabe decir que todavía queda un largo trecho hasta poder trazar una semblanza ajustada del canónigo medio español, pues los datos hasta ahora manejados se refieren a una parte muy pequeña de este amplio colectivo eclesiástico.

\section{BIBLIOGRAFÍA}

Ávila, J. de, Obras completas, Tomo VI, Madrid, BAC, 1971.

Barrio Gozalo, M., Estudio socioeconómico de la iglesia de Segovia en el siglo XVIII, Segovia, Caja de Ahorros de Segovia, 1982.

Beltrán Almazán, C. y Toledano Galera, J., «El cabildo de la IglesiaCatedral de Jaén en el siglo XVI. Organización y funcionamiento», Boletín del Instituto de Estudios Giennenses, 134 (1988), pp. 31-57.

Burgo LóPEZ, C., «La estructura económica del cabildo de Lugo a finales del siglo XVIII», Obradoiro de Historia Moderna, 2 (1993), pp. 65-84.

CABeZa Rodríguez, A., «Ingresos percibidos por los eclesiásticos de la catedral de Palencia durante la época moderna. Operaciones efectuadas en torno al reparto de las prebendas», Actas del II Congreso de Historia de Palencia, $\mathrm{Pa}$ lencia, III, 1990, pp. 483-498.

Cabeza Rodríguez, A., Clérigos y señores. Política y religión en Palencia en el Siglo de Oro, Palencia, Diputación Provincial, 1996.

Cabeza Rodríguez, A., La vida en una catedral del Antiguo Régimen, Palencia, Junta de Castilla y León, 1997.

CABEZA Rodríguez, A., «Entre mayorazgos y capillas. La oligarquía eclesiástica de Palencia en el siglo XVI», en ArANDA PÉrEZ, F. J. (Coord.), Socie- 
dad y élites eclesiásticas en la España moderna, Cuenca, Universidad de Castilla-La Mancha, 2000, pp. 35-46.

CÁnovas Botía, A., Auge y decadencia de una institución eclesial: el cabildo de Murcia en el siglo XVIII. Iglesia y sociedad, Murcia, Universidad de Murcia, 1994.

CASTILLÓN CORTADA, F., «Estructura del cabildo catedralicio de Lleida durante el siglo XVIII», Església i societat a la Catalunya del segle XVIII, Vol. II, Cervera, UNED, 1990, pp. 99-117.

Coronas Vida, L. J., «Los miembros del cabildo de la catedral de Jaén (1700-1737)», Chronica Nova, 15 (1986-1987), pp. 101-126.

Coronas Vida, L. J., «Los expedientes de limpieza de sangre en la catedral de Jaén», Códice, 2 (1987), pp. 83-90.

Cortés PeÑa, A. L., «Domínguez Ortiz y la historia social de la iglesia», Manuscrits, 14 (1996), pp. 39-57.

Domínguez OrTiz, A., «Documentos sobre estatutos de limpieza de sangre en las catedrales españolas», Miscelánea de Estudios Árabes y Hebraicos de la Universidad de Granada, XIV-XV (1967), pp. 33-42.

Domínguez Ortiz, A., La sociedad española en el siglo XVII. II. El estamento eclesiástico, Madrid, CSIC, 1970.

Durán Gudiol, A., «Notas para la historia de la Universidad de Huesca en el siglo XVI», Hispania Sacra, 21 (1968), pp. 87-154.

EGIDo LóPEZ, T., «El cabildo de Valladolid. Conflictos de jurisdicción», en Aranda Pérez, F. (Coord.), Sociedad y élites eclesiásticas en la España Moderna, Cuenca, Universidad de Castilla La Mancha, 2000, pp. 21-34.

FATJó Gómez, P., «Aproximación a una élite institucional de la Catalunya moderna: los capitulares de la seo de Barcelona en el siglo XVII», Pedralbes, 13-II (1993), pp. 149-162.

FATJÓ GóMEZ, P., «Organización y gestión de una hacienda eclesiástica en la Cataluña del XVII: la catedral de Barcelona», Revista de Historia Económica, XVII, 1 (1999), pp. 89-118.

Fernández Collado, A., La catedral de Toledo en el siglo XVI. Vida, Arte y Personas, Toledo, Diputación Provincial, 1999.

FERnÁndez Collado, A., «Grupos de poder en el cabildo toledano del siglo XVI», en ArAnda Pérez, F. J. (Coord.), Sociedad y élites eclesiásticas en la España moderna, Cuenca, Universidad de Castilla La Mancha, 2000, pp. 149-162.

FERnANDEZ DíAZ, R., «La clerecía catalana en el Setecientos», en Església $i$ societat a la Catalunya del segle XVIII, Vol. I, Cervera, UNED, 1990, pp. 23-118. 
GAN GiménEZ, P., «Los prebendados de la iglesia granadina: Una Bio-Bibliografía», Revista del Centro de Estudios Históricos de Granada y su Reino, 4 (1990), pp. 139-212.

García Figuerola, L. C., La economía del cabildo salmantino del siglo XVIII, Salamanca, Biblioteca de Castilla y León, 1989.

García y García, A., Historia del Derecho Canónico. I. El Primer Milenio, Salamanca, Instituto de Historia de la Teología Española, 1967.

García Pardo, M., El Cabildo de la Catedral de Jaén: organización y vida (siglos XIII-XVI), Almería, Servicio de Publicaciones de la Universidad de Almería (Microforma), 1998.

Gay Molins, P., «El cabildo de Santa María la Mayor de Zaragoza», Aragonia Sacra, XIII (1998), pp. 103-104.

GoÑ GaZTAMBIDE, J., «Los cabildos españoles y la confirmación del Concilio de Trento», Annuarium Historiae Conciliorum, 7 (1975), pp. 425-458.

Guerreau, A., El Feudalismo. Un horizonte teórico, Barcelona, Crítica, 1984.

HERNÁNDEZ Franco, J., «Limpieza de sangre en los cabildos catedralicios de la España Moderna. El estatuto del Cabildo de Murcia (1517-1750)», Homenaje a Antonio Bethencourt Massieu, Las Palmas, 1995, pp. 137-158.

HiLl, Ch., La revolución inglesa 1640, Barcelona, Anagrama, 1977.

IRIGOYEN LóPEZ, A., Entre el cielo y la tierra. Entre la familia y la institución. El cabildo de la catedral de Murcia en el siglo XVII, Murcia, Universidad de Murcia, 2000.

JiMÉNEZ SuREDA, M., L'Església catalana sota la monarquia dels Borbons: la catedral de Girona en el segle XVIII, Girona, Ajuntament de Girona/Publicacions de l'Abadia de Montserrat, 1999.

JoRdÁ FERnÁNDEZ, A., «Els canonges de la Seu de Tarragona durant el segle XVIII: aproximació al seu estudi», Església i societat a la Catalunya del segle XVIII, Cervera, UNED, 1990, pp. 255-265.

JoRdÁ FERnÁNDEZ, A., Església i poder a la Catalunya del segle XVII. La Seu de Tarragona, Barcelona, Abadía de Montserrat, 1993.

Latorre Ciria, J. M., «Los señoríos del cabildo de la catedral de Huesca (siglos XVI-XVII)», Jerónimo Zurita, 58 (1988), pp. 51-59.

LatorRe Ciria, J. M., Economía y religión. Las rentas de la catedral de Huesca y su distribución social (siglos XVI-XVII), Institución Fernando el Católico/Instituto de Estudios Altoaragoneses, Zaragoza-Huesca, 1992.

López Arévalo, J. R., Un Cabildo Catedral de la Vieja Castilla. Ávila: Su estructura jurídica, ss. XII-XX, Madrid, C.S.I.C., 1966. 
LóPez Celada, I., Evolución de las rentas del Cabildo de la catedral de Toledo durante el último cuarto del siglo XVI, Toledo, Caja de Ahorros Provincial de Toledo, 1980.

MaRín LóPez, R., El cabildo de la catedral de Granada en el siglo XVI, Granada, Universidad de Granada, 1998.

MARTín, T., «Primeras repercusiones tridentinas. El litigio de los cabildos españoles. Su proceso en la diócesis de Calahorra», Hispania Sacra, I (1948), pp. 325-349.

Martín Martín, J.L., El Cabildo de la Catedral de Salamanca (s.XII-XIII), Salamanca, Centro de Estudios Salmantinos, 1975.

Martínez Millán, J., «Las canonjías inquisitoriales», Hispania Sacra, XXXIV (1982), pp. 9-63.

Morgado García, A., Iglesia y sociedad en el Cádiz del siglo XVIII, Cádiz, 1989.

Morgado García, A., El estamento eclesiástico y la vida espiritual en la diócesis de Cádiz en el siglo XVII, Cádiz, Universidad de Cádiz, 1996.

Morgado García, A., «El alto clero gaditano durante el Antiguo Régimen (1600-1833)», Studia Histórica. Historia Moderna, 16 (1997), pp. 223-255.

Morgado García, A., Ser clérigo en la España del Antiguo Régimen, Cádiz, Universidad de Cádiz, 2000.

Morgado García, A., "Vida de canónigo. Percepción, origen y status de vida del alto clero durante el Antiguo Régimen», en ArAnda Pérez, F. J. (Coord.), Sociedad y élites eclesiásticas en la España Moderna, Cuenca, Ediciones de la Universidad de Castilla-La Mancha, 2000, pp. 77-100.

Moya Ulldemolins, J., «Aspectos económicos de la mesa capitular del cabildo catedral de Córdoba», Actas I Congreso Historia de Andalucía. Andalucía moderna, II, Córdoba, 1978, pp. 243-254.

MunIz, T., Derecho capitular. Cabildos Catedrales y Colegiales, Sevilla, 1917.

PAJARES AdREDO, L., «El cabildo catedralicio de Málaga desde su fundación hasta la guerra de la Independencia, bases para un estudio de la institución», Gibralfaro, 30 (1981), pp. 19-28.

PÉREZ ZAGorin, Revueltas y revoluciones en la Edad Moderna. I. Movimientos campesinos y urbanos, Madrid, Cátedra, 1985.

Piñero CARrión, J. M., «El canonicato como beneficio, líneas de evolución», Bibliotheca Salmanticensis. I. Estudios, 1 (1972), pp. 184-203.

Polo Rubio, J. J., «Beneficencia y caridad en los testamentos de canónigos turolenses durante los siglos XVI y XVII», Memoria Ecclesiae, X (1997), pp. 61-64. 
Quintanilla, M., «Provisión de prebendas de la Catedral», Estudios Segovianos, 10 (1959), pp. 525-530.

Rey CAstelao, O., «El alto clero gallego en tiempos de Carlos III», Coloquio internacional sobre Carlos III y su siglo, Vol. 2, Madrid, Dpto. de $\mathrm{H}^{\mathrm{a}}$. Moderna, Universidad Complutense, 1990, pp. 579-600.

San Martín, J., «El Cabildo de Palencia», Publicaciones de la Institución Tello Tellez de Meneses, 34 (1974), pp. 227-248.

SÁNCHEZ GonZÁLEZ, R., «Religiosidad barroca y sentimientos ante la muerte en el cabildo catedralicio de Toledo», Studia Histórica. Historia Moderna, 18 (1998), pp. 299-320.

SÁNCHEZ GonZÁLEZ, R., «Cabildo catedralicio y cabildo municipal en el Toledo moderno», en Bernardo Ares, J. M. y GonZÁlez Beltrán, J. M. (Eds.), La administración municipal en la Edad Moderna, Actas de la V reunión científica de la Asociación Española de Historia Moderna, Cádiz, 1999, pp. 137-146.

SÁNCHEZ GonzÁLEZ, R., Iglesia y sociedad en la Castilla moderna. El cabildo catedralicio de la sede primada (siglo XVII), Toledo, Universidad de Castilla La Mancha, 2000.

SÁnchez Herrero, J., «Vida y costumbres de los componentes del Cabildo catedral de Palencia a finales del siglo XV», Historia. Instituciones. Documentos, III (1976), pp. 485-532.

SÁnchez Herrero, J., «El cabildo catedral de Cádiz», Archivo Hispalense, 65 (1982), pp. 155-175.

VÁZQuez LESMES, R., «Los expedientes de información de limpieza de sangre del cabildo catedralicio cordobés», Actas II Coloquio de Andalucía. Andalucía Moderna, II, Córdoba, 1983, pp. 309-333.

VÁzQuez Lesmes, R., Córdoba y su cabildo catedralicio, Córdoba, 1987.

Villacorta Rodríguez, T., El Cabildo Catedral de León. Estudio históricojurídico. Siglos XII-XIX, León, Centro de Estudios e Investigación San Isidro, 1974. 